\title{
BROWN BEAR (URSUS ARCTOS) HABITAT SUITABILITY MODELLING AND MAPPING
}

\author{
SUEL, $\mathrm{H}$. \\ Department of Forestry, Sütçüler Vocational School, Isparta University of Applied Sciences \\ 32950 Isparta, Turkey \\ e-mail: halilsuel@isparta.edu.tr; phone: +90-530-153-0577; fax: +90-246-351-2901
}

(Received 20 $0^{\text {th }}$ Dec 2018; accepted 27 ${ }^{\text {th }}$ Feb 2019)

\begin{abstract}
Today, the biggest threats for mammal predators are habitat losses, humans, and other factors. Although brown bears are not under threat in Turkey, there is still risk for fragmented and isolated populations. It is necessary to carry out habitat suitability analysis in order to determine these risks. The study area is the Western Mediterranean Region and the modelling was carried out using Maximum Entropy method with presence data collected from 56 sample areas in Antalya - Akseki. MAXENT method was used since it reveals reliable and valid models in larger areas with little local data. Crossvalidation was done separating $90 \%$ of data for training and $10 \%$ for testing to validate test data in the modelling process. AUC values of the training and test data were found to be 0.956 and 0.909 , respectively. The model was also evaluated according to Receiver Operating Characteristic value and Jackknife test. Environmental variables contributing to the model were Ruggedness Index, Elevation, Slope, Normalized Difference Vegetation Index, Solar Illumination Index, and Roughness Index. Habitat suitability map of the brown bear was created following the modelling process and the usability of the model and the map were evaluated for brown bear management plans. To conclude, Brown bear is a significant mammal species the habitat of which must be preserved.
\end{abstract}

Keywords: environmental factor, jackknife, MAXENT, maximum entropy, ROC

\section{Introduction}

Populations and habitats of large predators are decreasing at a worrying rate due to anthropogenic effects, habitat fragmentation, and hunting activities. Brown bear, an important large mammal, are at a risk of disappearing as well (Nellemann et al., 2007; Roellig et al., 2014; Støen et al., 2015; Fernández-Gil et al., 2016). Brown bears having few individuals in isolated populations are stated to be under threat for spreading out in large areas, even though their total population is large and their IUCN red list category and criteria is LC (McLellan et al., 2017). Today, the majority of the brown bear population is isolated in mountainous regions under the effect of conservation activities (Swenson et al., 2000; Zedrosser et al., 2001). Although brown bears are stated to live in areas far from human pressure, a large part of the areas occupied by humans provide potentially optimal habitat conditions for the distribution of this species (Roellig et al., 2014). Despite this situation, populations living in the same space or being close to residential areas are under further threat and are more heavily isolated, as interaction among these populations are hindered due to many factors (McLellan et al., 2017). Thus, it is necessary to make conservation plans revealing actual and potential habitats for brown bears and other species.

Distributions, biology, and ecological needs of species should be known for their conservation status and action plans (Pacifici et al., 2015). Modelling and mapping of species habitat within a good planning is of great importance. MAXENT is known to be one of the most appropriate methods in habitat modelling studies of wild animal species. This method works well with presence data and gives correct results with little 
data. It is also based on modelling of relationships with environmental factors in areas where the species exists (Elith et al., 2006; Hernandez et al., 2006; Phillips et al., 2006).

In Turkey, brown bears live in deciduous forests, conifer forests, and mix forests up to a height of 3500 to $4000 \mathrm{~m}$, and in scrublands, shrubs, valleys being close to seas, alpine valleys, and cliffs (Başkaya et al., 2008; Ambarl1, 2012). Habitat variables of brown bears are height, anthropogenic factors, slope, roughness, roughness index, heat index, solar illumination index, and vegetation index as well as forests, open spaces, closedness, and ecological factors such as roads and climate (Apps et al., 2004; Ambarl1, 2012; Bojarska and Selva, 2012). Habitat type and quality play an important role in brown bear distribution (Can and Togan, 2004) and it is necessary to use environmental factors and to determine their effects on brown bear distribution in studies. Brown bears spread in the Black Sea and East Anatolian regions of Turkey densely (Ambarl1 et al., 2016). It is known that the species live in the Mediterranean region and (Turan, 1984) have intact and natural habitats in Antalya district (Can and Togan, 2004). When the distribution map of brown bears prepared in accordance with the IUCN data is examined, it is clearly seen that the species has disappeared in many areas and information regarding with their reproduction in their living areas are insufficient in the Mediterranean region (McLellan et al., 2017). In addition, populations of brown bear are fragmented and isolated in the Western Mediterranean region. This is seen to be a big threat for this species and it is important to determine the factors affecting its distribution and to reveal potential regions to maintain its continuity in the region. In other words, studies involving latest information regarding with the actual distribution and potential appropriate habitats of this species in the region should be done. This study aims to do suitability modelling and mapping to determine the distribution of brown bears in the Western Mediterranean region.

\section{Materials and method}

\section{Data collection}

West Mediterranean region in the south-west of Turkey was picked as the study area (Fig. 1). Inventory study was conducted in Akseki district to represent this region. West Taurus Mountains are surrounded by Bey Mountains, Elmalı Mountains, Katrancık Mountains, and Boncuk Mountains in the west and Akçalı Mountains, Geyik Mountains, Dedegöl Mountains, Kuyucak and Erenler Mountains in the east. There are many karstic shapes in this topography since this area is formed by limestone bedrock (Öztürk et al., 2018). The area is used extensively by locals for transhumance practices (Sar1, 2013). In this study, indirect observation technique was used in the collection of land data. Presence data of indirect inventory was obtained belonging to tracks, feces, and other signs of brown bears in 56 points Akseki district in 2016.

\section{Environmental variables}

Slope, Aspect, and Elevation maps of the region were created using Digital Elevation Model (DEM) on ArcMap 10.2 software. Topographic Position Index (TPI) was created using ArcMap 10.2 software with "Topography Tools "extension developed by Jennes (2016). Also, Topographic Convergence Index (TWI), Landform Classification (Jenness), Solar Illumination Index (6 am, 8 am, 10 am, noon, 2 pm, 4 pm, 6 pm, and 8 pm) (Tagil and Jennes, 2008) were created. Terrain Ruggedness Index (Ruggedness) 
was created via Terrain Tools extension (Riley et al., 1999). Roughness Index, (Roughness) and Heat load index (HLI) were created with the help of Geomorphometric and Gradient Metrics Toolbox. Beers Aspect (BA) (Eq. 1) (Beers et al., 1966) and topographic radiation index (TRASP) (Eq. 2) (Moisen and Frescino, 2002) values were calculated and maps were created using different equations, respectively.

$$
\begin{gathered}
\mathrm{BA}=\cos (\mathrm{Amax}-\mathrm{A})+1 \\
\text { TRASP }=[1-\cos ((\pi / 180)(\theta-30))] / 2
\end{gathered}
$$

Normalized Difference Vegetation Index (NDVI) was obtained from MOD13Q1 module, one of the satellite data of MODIS VI, monthly. (Didan et al., 2015). NDVI values range between $-2000(-0,2)$ and $10000(1,0)$. Negative values of NDVI show water bodies; values approximate to 0 show bare soil); values 0.1 and lower show barren areas of rock, sand, or snow; values between 0.2 and 0.3 show shrub and grassland, and values between 0.6 and 0.8 show temperate and tropical rainforests (Karaburun, 2010; Xei et al., 2010; Bhandari et al., 2012).

Climate data was downloaded on the following website (http://www.worldclim.org). Nineteen pieces bio-climate data were prepared (Hijmans et al., 2005). This climate data were cut according to the study area size and prepared according to 19 climatic data.

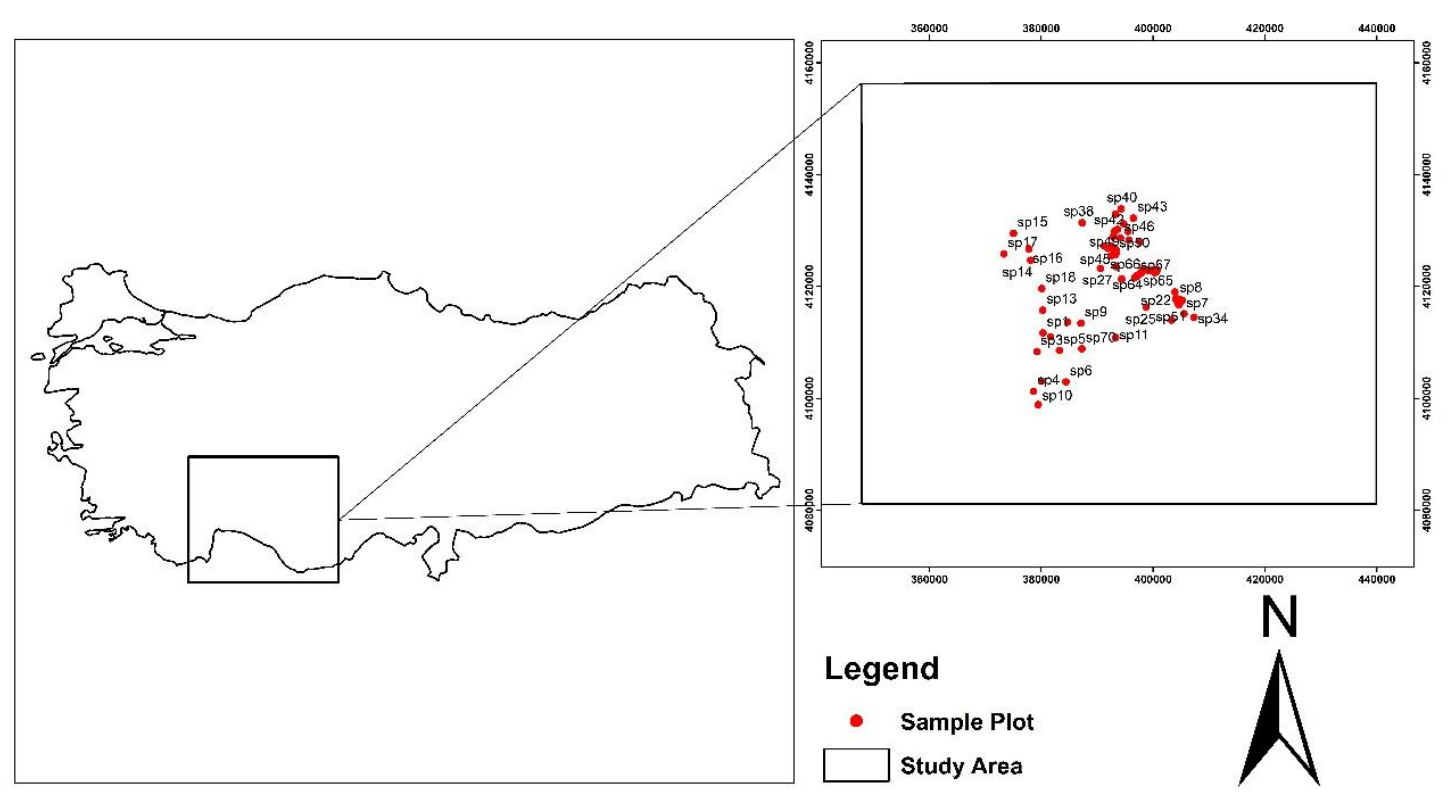

Figure 1. Study area and map of sample areas

\section{Modelling and mapping processes}

Factor analysis between elevation and nineteen bio-climate variables was applied in the modelling process in order to prevent independent variables from causing any bias. As a result of the analysis, elevation was chosen as representative variable since strong relationship between elevation and nineteen bio-climate variables might cause bias (Mert and Kıraç, 2017; Suel et al., 2018). After this process, potential habitat suitability modelling process was completed using MAXENT method. 
This method creates suitability model evaluating the data collected in the study area where the species exists and areas with similar features together (Baldwin, 2009). When compared to other modelling processes of presence data, MAXENT enables to create more realistic distribution and suitability models with less data (Phillips et al., 2004, 2006; Hernandez et al., 2006; Wisz et al., 2008; Baldwin, 2009; Elith et al., 2010).

3.4. $1 \mathrm{k}$ version of MAXENT is used for habitat suitability analysis. $90 \%$ of the brown bear presence data was allocated as training value and $10 \%$ was allocated as test value and modelled with environmental variables. The success of MAXENT model was assessed using ROC (Receiver Operating Characteristic) curves; AUC values of training-test data and their contribution to model levels were assessed with jackknife graphs (Deleo, 1993; Fielding and Bell, 1997; Phillips et al., 2006; Baldwin, 2009; Monterroso et al., 2009). Potential distribution map ranging between 0 and 1 was illustrated in ArcMap 10.2 software (Özkan et al., 2015)

\section{Results}

A successful and valid model with the ROC value of 0.956 was obtained in this study (Fig. 2). AUC value of the test data is 0.909 whereas AUC value of training data is higher than test data, yet the discrepancy is not high. However, the area under the ROC curve is higher than the area under the random prediction line. These results show that the model can be used as it gives realistic results.

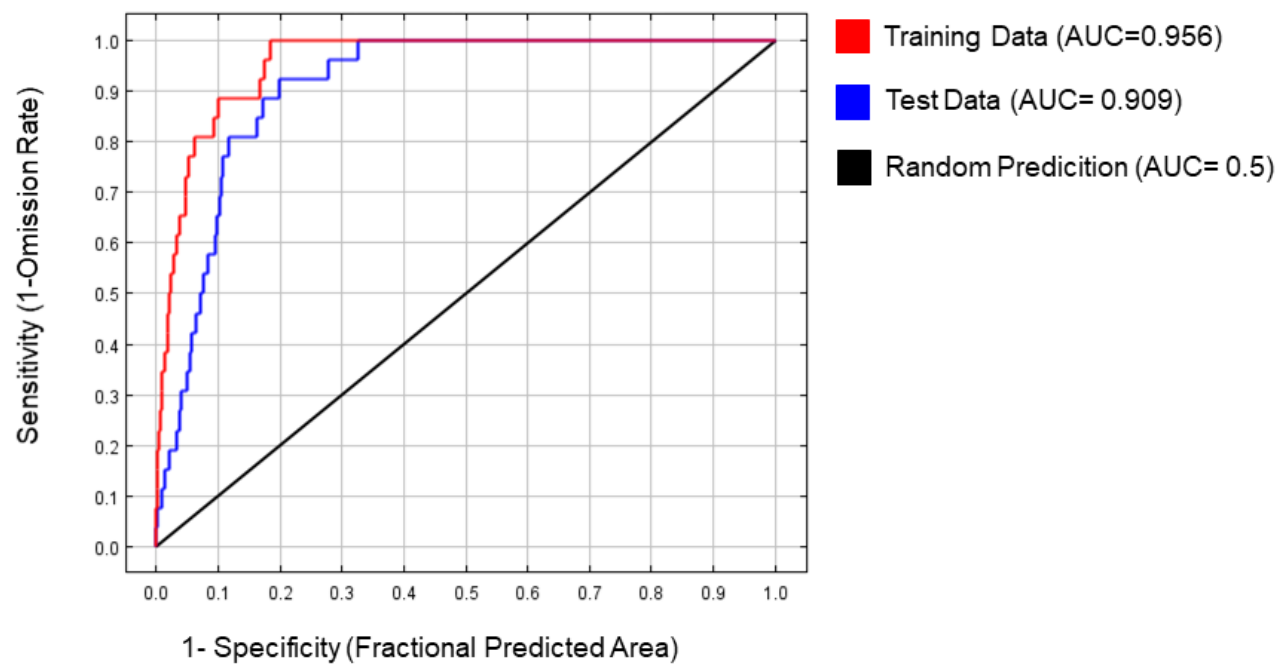

Figure 2. ROC and AUC MAXENT values of the model

Environmental variables are $2 \mathrm{pm}, 6$ am, Elevation, Slope, NDVI (September), Roughness, and Ruggedness (Table 1). Variables that contribute most to the model are roughness, elevation, and NDVI (Table 1).

When the results of jackknife statistics are examined, it is seen that ruggedness makes the most contribution to the model. Although the contribution level of roughness is high, excluding it would not cause a great loss in the model, in which case it can be said that elevation is more descriptive compared to roughness and thus is the second highest contributor of the model. Another significant variable in terms of model gain is 
NDVI. 6 am and slope also play a role in the model's success. 2 pm has the lowest contribution alone and in terms of total model gain (Fig. 3).

Table 1. Variables contributing to the model and their contribution levels

\begin{tabular}{c|c}
\hline Environmental variable & Contribution \% \\
\hline Ruggedness & 59.9 \\
Elevation & 23 \\
NDVI & 9.2 \\
6 am & 3.1 \\
Slope & 2.5 \\
Roughness & 1.6 \\
2 pm & 0.8 \\
\hline
\end{tabular}

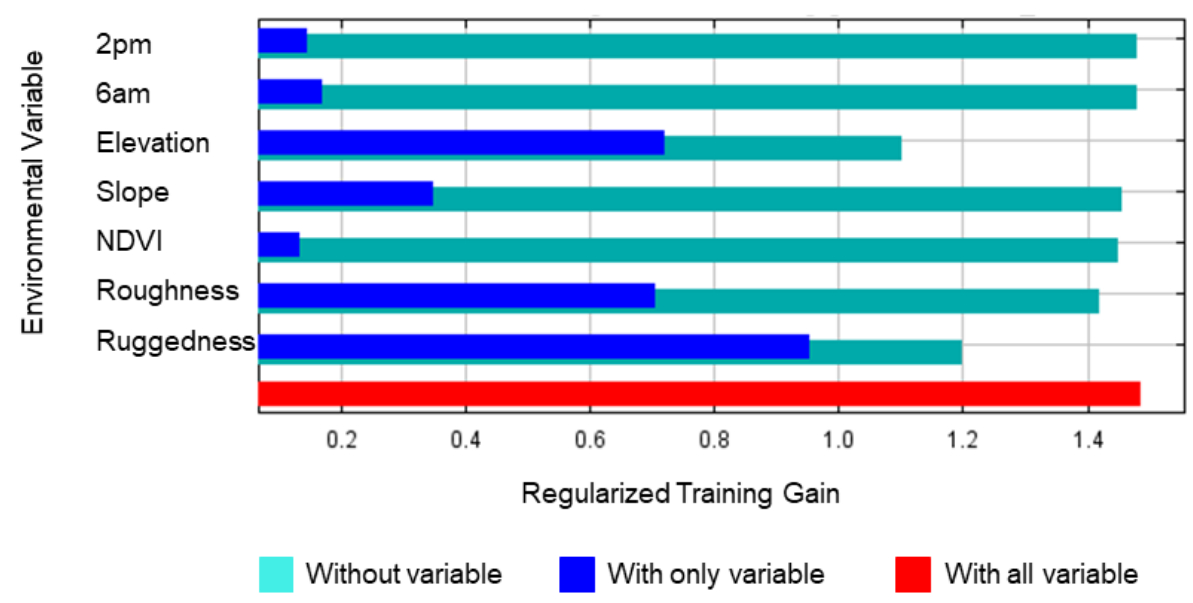

Figure 3. Jackknife test for evaluating the relative importance of environmental variables

Three variables making the most contribution to the model in percentages are ruggedness, elevation, and NDVI and when examined together with roughness, the highest contributor according to jackknife results, it is seen that brown bears prefer rugged areas up to a specific point and avoid extremely rugged terrains topographically (Fig. 4).

Elevation has a positive effect on the habitat of this specific species up to about $2000 \mathrm{~m}$ whereas this effect becomes negative in higher locations. In terms of NDVI results, it is seen that brown bears prefer natural, open areas and forests and avoid dense forests. Finally, these species prefer rough areas up to a point meaning it avoids flat spaces (Fig. 4).

The scale regarding with the potential habitat suitability of brown bear on the habitat suitability map ranges between 0 and 0.97 . Red areas are the most suitable habitats potentially whereas blue areas show unsuitable terrains for brown bears (Fig. 5). Currently, brown bear populations are available in Kuyucak, Civikli, Geyik and Gidengelmez Mountains and their surroundings. Although there is no brown bear population apart from these areas such as Akçal, Cehennem, Aygır, Çamurlu and Gelincik mountains, model results reveal these as potential habitats for brown bears. 
Akcal Mountain and the area in its east part are suitable for brown bears, but there is no sufficient data regarding with whether brown bears exist in this area or not.
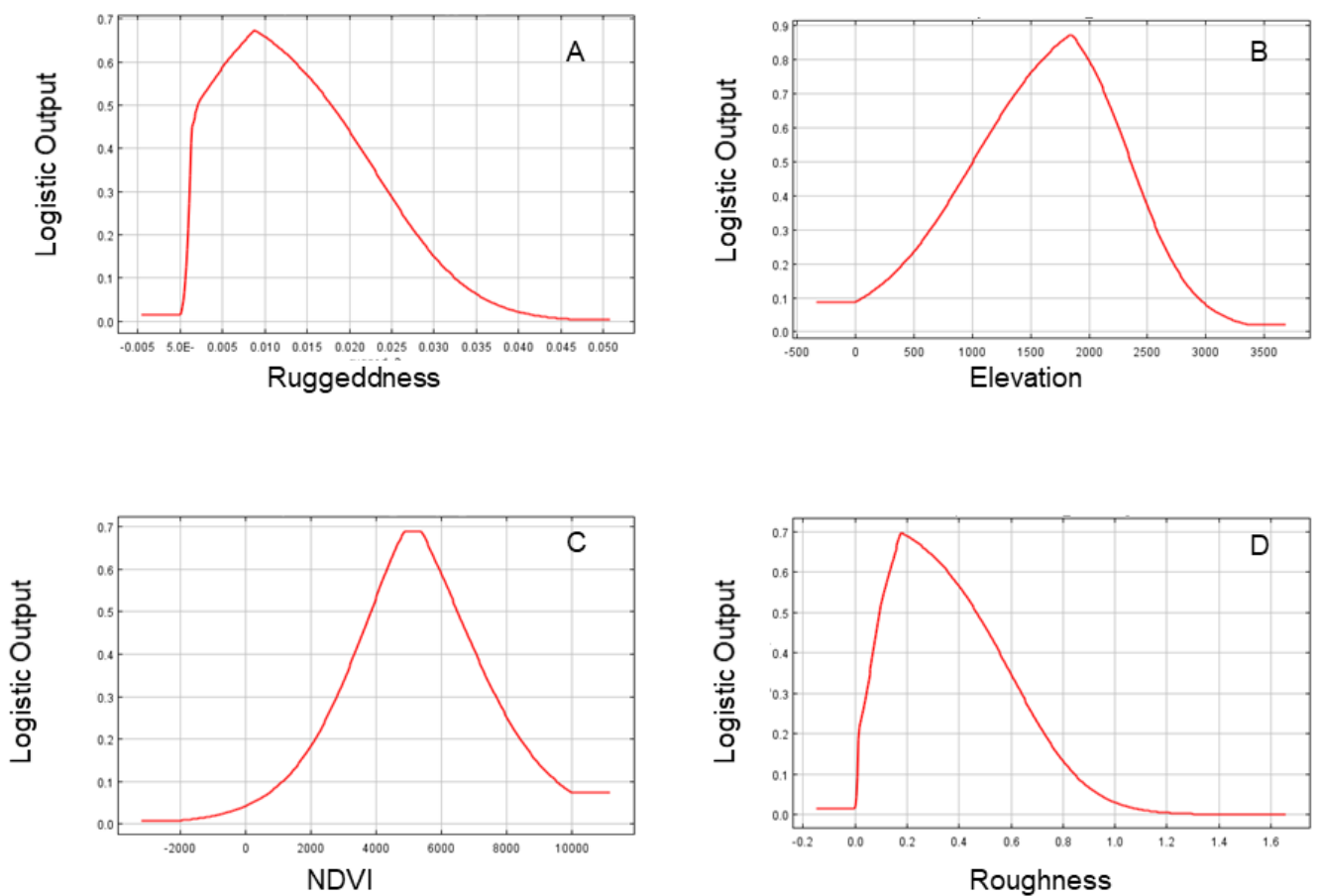

Figure 4. Important factor response curve: $(A)$ ruggedness index, $(B)$ elevation, $(C)$ NDVI; $(D)$ roughness index

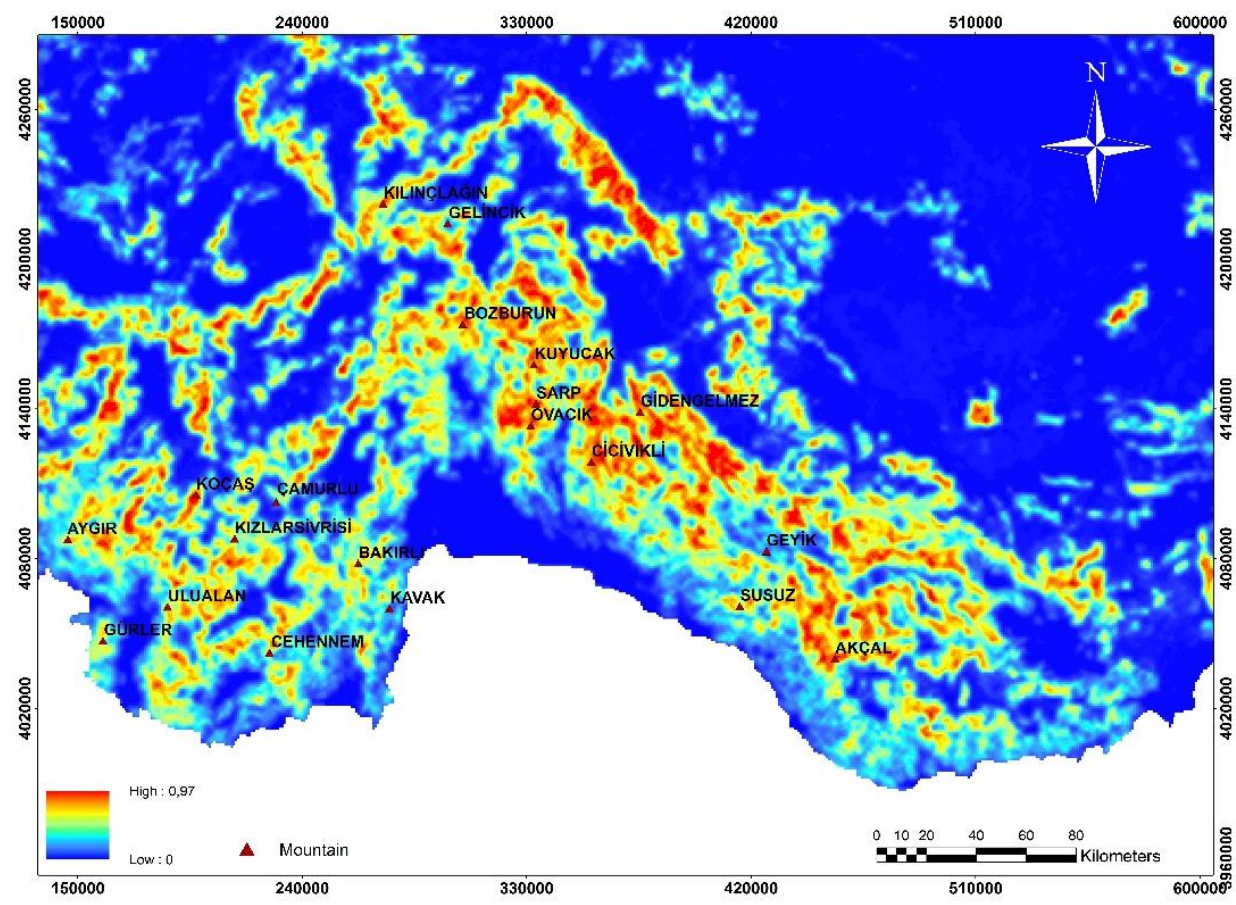

Figure 5. Habitat suitability map of brown bears 


\section{Discussion}

Modelling studies provide significant guide for potential distribution and habitat suitability maps of animal and plant species. In terms of its topographic structure, forests, and geographical location, West Mediterranean Region deserves its potential to be revealed (Özkan et al., 2015). In this study, habitat suitability modelling and mapping of brown bears were performed. Although the data is relatively little and involves a local area, successful and real results were obtained thanks to the MAXENT method. The model was verified via ROC graph, difference between training (AUC: 0.956) and test values (AUC: 0.909), and jackknife tests (Phillips et al., 2006; Wisz et al., 2008; Baldwin, 2009; Elith et al., 2010; Tekin et al., 2018). Both researchers and executors can use the habitat suitability map.

Variables forming the MAXENT model are Elevation, Slope, Solar Illuminations Index, Ruggedness Index, Roughness Index, and NDVI according to their contribution percentages and the results of jackknife test. These results show that rugged areas play an important role in brown bear distribution and brown bears prefer areas with specific slope degrees. In previous studies, slope is stated to be a significant environmental factor that affects habitat preferences of brown bears (Štofik, and Saniga, 2012). When topographic structure of West Taurus Mountains is considered, it is understood that it is an expected situation for slope to contribute to the model in especially cliffy areas and that brown bears do not prefer excessively sloped areas. Ruggedness is also another important variable in habitats potentially suitable for brown bears and previous studies point out that brown bears prefer rugged terrains for they are not affected by human activities and rich in terms of vegetation (Apps et al., 2004; Nielsen et al., 2004; Nellemann et al., 2007.).

It was observed in field studies that rugged areas with their local vegetation in West Taurus Mountains, which form the topography in the West Mediterranean Region, overlap with areas where there are brown bears. Field studies carried out in Akseki district show that brown bears choose rugged areas with rich vegetation. Moreover, Brown bears use rugged areas where there is Juniperus drupacea for nutrition and use some other rugged fields for shelter. As for roughness index, brown bears are seen to avoid flat and extremely rough surfaces and use rough areas for daily activities. Although there is not clear information about this in the literature, roughness index overlaps and shows similarities with other variables such as ruggedness and slope.

The natural forests in altitudes between 500 and $2000 \mathrm{~m}$ in Western Mediterranean have been found to be ideal habitats for brown bears. Can and Togan (2004) stated the terrains with same features are potential habitats for brown bears. In addition, the reason why brown bears prefer altitudes between 800 and $1000 \mathrm{~m}$ as habitat is related to vegetation, human impact and land structure (Posillico et al., 2004). The information here overlaps with the interpretations related to ruggedness as mentioned above and the effects of this can be clearly seen in brown bear distribution map.

NDVI was determined as a significant variable that contributes to habitat suitability model of the brown bear- an omnivorous living being and this reveals that brown bears prefer to live in areas where there are dense natural forests in the Western Mediteranean region. This overlaps directly with the living spaces of brown bears where there are coniferous trees or mix forests. The relationship between habitat preferences of brown bears and NDVI was revealed in previous studies, brown bears have been found to prefer green vegetation (Can and Togan, 2004; Bojarska and Selva, 2012). 
This study found out that Solar Illuminations index contributes to the habitat suitability model, though this contribution is small. It is therefore understood that brown bears prefer noon to early morning hours and avoid extensive sunlight. It was pointed out in the literature that brown bears are more active during day in shorter days of the year (Ordiz et al., 2012) and that there are differences in their daily activities by seasons and light period (Ware et al., 2018). Hence, all these results show that brown bears react to sunlight, yet this situation might differ by seasons.

The habitat suitability map shows that our map is consistent with the distribution maps presented in the literature (Ambarlı et al., 2016; McLellan et al., 2017). Besides, the habitat suitability map shows potential areas for brown bears. Suitable areas for brown bears in the Western Mediterranean region were presented on the map.

\section{Conclusion}

In conclusion, habitat suitability modelling and mapping study was carried out successfully in the Western Mediterranean region and supported with the literature. The actual state and potential distribution areas of the species under the effect of basic environmental variables that affect habitats of brown bears were revealed. In fact, brown bears are not under the threat of extinction; however, they are large mammals and their populations are divided, they are also in the risky group. This study determined habitat factors of and potential areas for brown bears and this is of great importance for action plans to be prepared. Thus, the findings of this study are expected to provide guidance for action plans to be created for this species.

Acknowledgements. The author would like to express special thanks to Serkan ÖZDEMIR, Murat ERCAN and Ahmet MERT practical support of the work. We thank to project 4752-YL1-16 supported by the Coordination Unit for Scientific Research Projects, Süleyman Demirel University.

\section{REFERENCES}

[1] Ambarl1, H. (2012): Spatio-temporal ecology, habitat use and population size of brown bears (Ursus arctos) in Yusufeli, Turkey. - PhD Thesis. Middle East Technical University, Ankara, Turkey.

[2] Ambarl1, H., Ertürk, A., Soyumert, A. (2016): Current status, distribution, and conservation of brown bear (Ursidae) and wild canids (gray wolf, golden jackal, and red fox; Canidae) in Turkey. - Turkish Journal of Zoology 40(6): 944-956.

[3] Apps, C. D., McLellan, B. N., Woods, J. G., Proctor, M. F. (2004): Estimating grizzly bear distribution and abundance relative to habitat and human influence. - The Journal of Wildlife Management, 68(1): 138-152.

[4] Baldwin, R. A. (2009): Use of maximum entropy modeling in wildlife research. Entropy 11(4): 854-866.

[5] Başkaya, Ş., Başkaya, E., Bilgili, E., Gülci, S. (2008): Population status and pricipal threats for big carnivores in Alpine areas of Turkey. - 82nd Annual Meeting of the German Society of Mammalogy (Deutsche Gesellschaft für Säugetierkunde e.V.), September 14-17, Vienna, Austria.

[6] Beers, T. W., Dress, P. E., Wensel, L. C. (1966): Notes and observations: aspect transformation in site productivity research. - Journal of Forestry 64(10): 691-692. 
[7] Bhandari, A. K., Kumar, A., Singh, G. K. (2012): Feature extraction using normalized difference vegetation index (NDVI): A case study of Jabalpur city. - Procedia Technology 6: 612-621.

[8] Bojarska, K., Selva, N. (2012): Spatial patterns in brown bear Ursus arctos diet: the role of geographical and environmental factors. - Mammal Review 42(2): 120-143.

[9] Can, O. E., Togan, I. (2004): Status and management of brown bears in Turkey. - Ursus 15(1): 48-53.

[10] Deleo, J. M. (1993): Receiver operating characteristic laboratory (ROCLAB): software for developing decision strategies that ac-count for uncertainty. - Proceedings of the Second International Symposium on Uncertainty Modelling and Analysis, College Park, MD. IEEE Computer Society Press.

[11] Didan, K., Munoz, A. B., Solano, R., Huete, A. (2015): MODIS Vegetation Index User's Guide (MOD13 Series). - University of Arizona: Vegetation Index and Phenology Lab., Arizona.

[12] Elith, J., Graham, C. H., Anderson, R. P., Dudık, M., Ferrier, S., Guisan, A., Hijmans, R. J.,Huettmann, F., Leathwick, J. R., Lehmann, A., Li, J., Lohmann, L. G., Loiselle, B. A., Manion, G.,Moritz, C., Nakamura, M., Nakazawa, Y., Overton, J. McC., Peterson, A. T., Phillips, S. J.,Richardson, K. S., Scachetti-Pereira, R., Schapire, R. E., Sobero' n, J., Williams, S., Wisz, M. S., Zimmermann, N. E. (2006): Novel methods improve prediction of species' distributions from occurrence data. - Ecography 29: 129-151.

[13] Fernández-Gil, A., Naves, J., Ordiz, A., Quevedo, M., Revilla, E., Delibes, M. (2016): Conflict misleads large carnivore management and conservation: brown bears and wolves in Spain. - PLoS One 11(3): e0151541.

[14] Fielding, A. H., Bell, J. F. (1997): A review of methods for the measurement of prediction errors in conservation presence/absence models. - Environmental Conservation 24: 38-49.

[15] Hernandez, P. A., Graham, C. H., Master, L. L., Albert, D. L. (2006): The effect of sample size and species characteristics on performance of different species distribution modeling methods. - Ecography 29(5): 773-785.

[16] Hijmans, R. J., Cameron, S. E., Parra, J. L., Jones, P. G., Jarvis, A. (2005): Very high resolution interpolated climate surfaces for global land areas. - International Journal of Climatology 25(15): 1965-1978.

[17] Jenness, J. (2006): Topographic Position Index (tpi_jen. avx) Extension for ArcView 3. x Version 1.2. - Jenness Enterprises, Flagstaff, AZ.

[18] Karaburun, A. (2010): Estimation of C factor for soil erosion modeling using NDVI in Buyukcekmece watershed. - Ocean Journal of Applied Sciences 3: 77-85.

[19] McLellan, B. N., Proctor, M. F., Huber, D., Michel, S. (2017): Ursus arctos. The IUCN Red List of Threatened Species 2017: e.T41688A121229971. http://dx.doi.org/10.2305/IUCN.UK.2017- 3.RLTS.T41688A121229971.en.

[20] Mert, A., Kıraç, A. (2017): Habitat suitability mapping of Anatololacerta danfordi (Günter, 1876) in Isparta-Sütçüler District. - Bilge International Journal of Science and Technology Research 1(1): 16-22.

[21] Moisen, G. G., Freeman, E. A., Blackard, J. A., Frescino, T. S., Zimmermann, N. E., Edwards, T. C. (2006): Predicting tree species presence and basal area in Utah: a comparison of stochastic gradient boosting, generalized additive models, and tree-based methods. - Ecological Modelling 199: 176-187.

[22] Monterroso, P., Brito, J. C., Ferreras, P., Alves, P. C. (2009): Spatial ecology of the European wildcat in a Mediterranean ecosystem: dealing with small radio-tracking datasets in species conservation. - Journal of Zoology 279: 27-35.

[23] Nellemann, C., Støen, O. G., Kindberg, J., Swenson, J. E., Vistnes, I., Ericsson, G., Katajisto, J., Kaltenborn, P. B., Martin, J., Ordiz, A. (2007): Terrain use by an expanding brown bear population in relation to age, recreational resorts and human settlements. Biological Conservation 138(1-2): 157-165. 
[24] Nielsen, S. E., Herrero, S., Boyce, M. S., Mace, R. D., Benn, B., Gibeau, M. L., Jevons, S. (2004): Modelling the spatial distribution of human-caused grizzly bear mortalities in the Central Rockies ecosystem of Canada. - Biological Conservation 120: 101-113.

[25] Ordiz, A., Støen, O. G., Sæbø, S., Kindberg, J., Delibes, M., Swenson, J. E. (2012): Do bears know they are being hunted? - Biological Conservation 152: 21-28.

[26] Özkan, K., Sentürk, Ö., Mert, A., Negiz, M. G. (2015): Modeling and mapping potential distribution of Crimean juniper (Juniperus excelsa Bieb.) using correlative approaches. Journal of Environmental Biology 36(1): 9.

[27] Öztürk, M. Z., Şimşek, M., Şener, M. F., Utlu, M. (2018): GIS based analysis of doline density on Taurus Mountains, Turkey. - Environmental Earth Sciences 77(14): 536.

[28] Pacifici, M., Foden, W. B., Visconti, P., Watson, J. E., Butchart, S. H., Kovacs, K. M., Scheffers, B. R., Hole, D. G., Martin, T. G., Akçakaya, H. R., Corlett, R. T., Huntley, B., Bickford, D., Carr, J. A., Hoffmann, A. A., Midgley, G. F., Pearce-Kelly, P., Pearson, R. G., Williams, S. E., Willis, S. G., Young, B., Rondinini, C. (2015): Assessing species vulnerability to climate change. - Nature Climate Change 5(3): 215-224.

[29] Phillips, S. J., Dudík, M., Schapire, R. E. (2004): A maximum entropy approach to species distribution modeling. - Proceedings of the Twenty-First International Conference on Machine Learning, ACM, Canada.

[30] Phillips, S. J., Anderson, R. P., Schapire, R. E. (2006): Maximum entropy modeling of species geographic distributions. - Ecological Modelling 190: 231-259.

[31] Posillico, M., A. Meriggi, E. Pagnin, S. Lovari, Russo, L. (2004): A habitat model for brown bear conservation and land use planning in the central Apennines. - Biological Conservation 118: 141-150.

[32] Riley, S. J., DeGloria, S. D., Elliot, R. (1999): A terrain ruggedness index that quantifies topographic heterogeneity. - Intermountain Journal of Sciences 5(1-4): 23-27.

[33] Roellig, M., Dorresteijn, I., Von Wehrden, H., Hartel, T., Fischer, J. (2014): Brown bear activity in traditional wood-pastures in Southern Transylvania, Romania. - Ursus 25(1): 44-52.

[34] Sarı, C. (2013): Functional change processes of plateaus and festivals in West Taurus. International Journal of Geography and Geography Education (IGGE) 27: 242-261.

[35] Støen, O. G., Ordiz, A., Evans, A. L., Laske, T. G., Kindberg, J., Fröbert, O., Swenson, J. E., Arnemo, J. M. (2015): Physiological evidence for a human-induced landscape of fear in brown bears (Ursus arctos). - Physiology \& Behavior 152: 244-248.

[36] Štofík, J., Saniga, M. (2012): Dens and beds of the brown bear Ursus arctos in the Eastern Carpatian region - Poloniny National Park. - Folia Oecologica 39(2): 147-154.

[37] Suel, H., Mert, A., Yalcinkaya, B. (2018): Changing potential distribution of gray wolf under climate change in Lake district, Turkey. - Applied Ecology and Environmental Research 16(5): 7129-7137.

[38] Swenson, J. E., Gerstl, N., Dahle, B., Zedrosser, A. (2000): Action Plan for the Conservation of the Brown Bear in Europe. - WWF International, Gland, Switzerland.

[39] Tagil, S., Jenness, J. (2008): GIS-based automated landform classification and topographic, landcover and geologic attributes of landforms around the Yazoren Polje, Turkey. - Journal of Applied Sciences 8: 910-921.

[40] Tekin, S., Yalçınkaya, B., Acarer, A., Mert, A. (2018): A research on usage possibilities of satellite data in wildlife: Modeling habitat suitability of Roe deer (Capreolus capreolus L.) with MaxEnt. - Bilge International Journal of Science and Technology Research 2(2): 147-156.

[41] Turan, N. (1984): Türkiye'nin Av ve Yaban Hayvanları: Memeliler. 1. Kitap. - Özel Yayın, Ankara (in Turkish).

[42] Ware, J. V., Nelson, O. L., Robbins, C. T., Jansen, H. T. (2012): Temporal organization of activity in the brown bear (Ursus arctos): roles of circadian rhythms, light, and food entrainment. - American Journal of Physiology-Regulatory, Integrative and Comparative Physiology 303(9): R890-R902. 
[43] Wisz, M. S., Hijmans, R., Li, J., Peterson, A. T., Graham, C., Guisan, A. (2008): Effects of sample size on the performance of species distribution models. - Diversity and Distributions 14(5): 763-773.

[44] Xie Y, Zhao X, Li L, Wang, H. (2010): Calculating NDVI for landsat7-etm data after atmospheric correction using 6s model: a case study in Zhangye City, China. Proceedings of IEEE Geoinformatics 18th International Conference on Digital Object Identifier, Beijing.

[45] Zedrosser, A., Dahle, B., Swenson, J. E., Gerstl, N. (2001): Status and management of the brown bear in Europe. - Ursus 12: 9-20. 